\title{
O Rio de Janeiro sob a pena de Joaquim Manuel de Macedo
}

\author{
Tiago Pedruzzi*
}

\begin{abstract}
Resumo: Este trabalho tem por objetivo analisar a representação da então capital imperial, feita por Joaquim Manuel de Macedo, em seu livro de crônicas Um Passeio pela cidade do Rio de Janeiro. Averiguar como é feito esse construto e como se dá a incorporação da cidade real pela cidade letrada, conceitos utilizados por Ángel Rama para caracterizar o binômio constitutivo do espaço urbano. Demonstrar que a cidade física, com seus prédios, paisagens e monumentos, é motivo para a fixação da memória da cidade real e que a sua incorporação pelo núcleo urbano letrado é tanto objetivo da cidade letrada como do movimento artístico da época, o Romantismo.
\end{abstract}

Palavras-chave: cidade; Rio de Janeiro; crônicas; representação; nação.

\begin{abstract}
This study analyzes the representation of the former Imperial capital as depicted by Joaquim Manoel de Macedo in his book of lyric essays Um Passeio pela cidade do Rio de Janeiro (A walk through the city of Rio de Janeiro); It also investigates how this construct is built and how the real city is incorporated by the literate city, concepts used by Ángel Rama to characterize the elements which constitute the urban space; it demonstrates that the city, with its buildings, landscapes and monuments is a reason for fixating the real city memory and that its incorporation by the literate urban elite is the objective of not only the literate city but also of the Romanticism, the artistic movement which was prominent at the time.
\end{abstract}

Keywords: city; Rio de Janeiro; liric essay, representation, nation.

Um passeio pela cidade do Rio de Janeiro de Joaquim Manuel de Macedo, é um livro de crônicas publicadas primeiramente no Jornal do Comércio, entre 1862 e 1863. Como o título indica, cada capítulo do livro ou crônica corresponde a um passeio realizado em algum ponto da cidade do Rio de Janeiro em companhia do cronista. A crítica geralmente esquece, voluntária ou involuntariamente, essa faceta de cronista de Macedo, diminuindo a avaliação de sua produção literária, lembram-se do autor de A Moreninha e deixam de lado toda sua produção como cronista e arguto observador dos costumes da cidade do Rio de Janeiro. O relato feito pelo autor em suas crônicas privilegia a descrição dos locais da cidade do ponto de vista das características físicas e históricas da cidade, criando um caráter diferenciado, tornando ainda agradável aos leitores atuais. No entanto, não é apenas uma mera descrição da cidade física o que constitui o texto de Macedo. A cidade física, nesse caso o Rio de Janeiro Imperial, é motivo para o autor construir a representação da cidade, essa construção se dá através do conjunto de elementos presentes no espaço físico da urbe. A cidade torna-se porta-

\footnotetext{
* Graduando e Bolsista PIBIC/CNPq
} 
dora do passado como bem representa Italo Calvino em As Cidades Invisíveis ao descrever a cidade de Zaíra:

[...] a cidade não conta seu passado, ela o contém como as linhas da mão, escrito no ângulo das ruas, nas grades das janelas, nos corrimãos das escadas, nas antenas dos pára-raios, nos mastros das bandeiras, cada segmento riscado por arranhões serradelas, entalhes, esfoladaura. Cidades invisíveis, (CALVINO, 2003, p. 16)

Já no primeiro passeio que o cronista faz, esta construção mediada pelo ambiente físico fica bastante evidente. A descrição do Palácio Imperial evoca a sua história, e o autor e sua memória não se eximem de decodificar estas marcas da cidade e sistematizá-las, como nos aponta o trecho a seguir: "Eis-nos em frente do palácio imperial, no longo do Paço [...] Paremos agora um pouco e conversemos por dez minutos. É justo que estudemos com interesse a história do Palácio Imperial”(MACEDO, 2005, p.31).

O autor busca, constantemente, construir uma representação da cidade, e para analisar essa tarefa devemos entender a cidade como o 'reflexo' não mimético de uma cidade física, ou seja, pensada e formulada no imaginário a partir de uma junção de signos que compõem uma identidade social e culturalmente construída (cf. PESAVENTO, 2002, p.158).

Essa articulação de signos é a imagem da cidade real que partindo da concepção sausseriana de signo lingüístico utilizada por Ángel Rama (1985, p.52) “[...] trabalha mais comodamente no campo dos significantes e inclusive os afasta dos encadeamentos lógicogramaticais". Na outra ponta temos a cidade letrada que "atua preferencialmente no campo das significações e inclusive as autonomiza em um sistema [...]” (RAMA, 1985, p.52)

Na tentativa de sistematizar a capital fluminense, papel fundamental da cidade letrada, o cronista ao ler a articulação dos signos da cidade busca fixar a cidade real, essa atitude dáse por meio de dois recursos: os típicos da cidade letrada; pesquisa em livros de história, crônicas de época, documentos tangíveis e verificáveis e os relatos orais calcados na tradição e mais consoantes com a cidade real.

Irei referir de envolta com alguns fatos registrados nas crônicas do tempo uma ou duas tradições populares. Colhi os primeiros nos livros e memórias que consultei, e as segundas contoumas um padre velho que morreu há dez anos. Daqueles não é lícito duvidar; a estas pode negarse crédito sem receio de molestar o padre, que já não tem que ver com as cousas deste mundo. (MACEDO, 2005, p.58).

Apesar de estigmatizar o relato oral desqualificando-o, o cronista tem a necessidade de apresentá-lo, aqui se interpenetram duas interpretações da cidade, mesmo que, uma seja preterida em relação à outra. $\mathrm{O}$ narrador valoriza o documento, privilegia a letra impressa como se pode notar nesse outro trecho:

Que fiz eu? Procurei amenizar a história, escrevendo-a com esse tom brincalhão e às vezes epigramático que, segundo dizem, não lhe assenta bem, mas de que o povo gosta; juntei à história verdadeira os tais ligeiros romances, tradições inaceitáveis e lendas inventadas para falar à i- 
maginação e excitar a curiosidade do povo que lê, e que eu desejo que leia os meus Passeios; mas nem uma só vez deixei de declarar muito positivamente qual o ponto onde a intenção se mistura com a verdade. (MACEDO, 2005, p.25).

Rama afirma que essa preferência pela palavra escrita é típica da cidade letrada, pois na América Latina ela era muitas vezes vista como a única que possuía rigidez e permanência e que buscava imitar a eternidade, o que não acontecia com a palavra falada que pertencia ao reino das coisas precárias e inseguras (cf. RAMA, 1985, p.29).

Joaquim Manuel de Macedo mesmo não dando crédito à tradição oral, ou seja, o discurso da cidade real, faz uso dela como no trecho a seguir em que o cronista busca explicar a origem do passeio público a partir da história de amor secreto do vice-rei:

Esta historieta, tradição ou coisa que o valha, que aliás daria origem um pouco romanesca ao nosso Passeio Público, só poderia ter trans-pirado por uma indiscrição de mestre Valentim, ou porque Susana houvesse adivinhado o segredo do gênio do seu sonho de moça. Em qualquer dos casos, acaba, porém, de um modo que não desmente, antes faz honra ao caráter generoso de Luís de Vasconcelos. Se ainda assim não quiserem aceitar a tradição por lhe faltar seguro fundamento, roguem-me pragas ou critiquem-me à vontade, que nem por isso deixarei de passear. (MACEDO, 2005, p.96).

Essa caracterização talvez se deva a tentativa de "constituição da literatura, como discurso sobre a formação, composição e definição da nação" (RAMA, 1985, p.93). Fator esse, que permitia, como disse Rama (1985, p.93) “a incorporação de múltiplos materiais alheios ao círculo anterior das belas letras que emanavam das elites cultas, mas implicava, além disso, uma prévia homogeneização e higienização do campo, o que somente podia ser realizado pela escritura".

O autor usa da tradição ou a inventa mesmo sabendo que não será aceita por uma parcela de seus leitores, ávidos pelo sólido, pelo documento histórico e não por historietas e sonhos, coisas intangíveis da cidade real.

Ainda no campo da apreensão do popular pelo erudito, temos uma espécie de conselho dado pelo autor de $A$ moreninha a quem se aventurar por fazer uma música genuinamente brasileira. Ele recorda-se da 'originalidade' dos cantos ouvidos na infância e de suas características únicas:

Cuja música tinha um caráter que a fazia distinguir da música característica de todas as outras nações, têm-se ido perdendo pouco a pouco, sacrificada ao canto italiano, cuja imitação é, desde alguns anos, o pensamento dominante dos nossos compositores. As modinhas e os lundus brasileiros quase que já não existem senão na memória dos antigos; foram banidos dos salões elegantes. (MACEDO, 2005, p,90).

O autor não se isenta de aconselhar aos futuros compositores que buscam fazer uma música nacional que se fiem no exemplo das músicas populares que povoam a tradição popular brasileira: 
[...] para a música característica brasileira isso é uma verdadeira calamidade, e a Ópera Nacional, recentemente criada, se quiser ser nacional, deve opor-se à continuação de tão grave erro, excitando os nossos novos e talentosos compositores a escreverem naquele gosto que, bem aproveitado pela arte, pode produzir obras originais e de incontestável merecimento. (MACEDO, 2005, p. 90).

Há uma preocupação em definir a nação por parte da cidade letrada, mas nesse caso ainda há outros fatores que regem esse nacionalismo apresentado por Macedo. Dentre esses fatores, destacamos a jovialidade da nação brasileira que conta com apenas quarenta anos de existência, mas, além disso, o caráter nacionalista do espírito de época, o Romantismo. Como bem delibera Macedo Soares (apud CANDIDO, 1997, p.12) a literatura tinha o papel de “compreender a natureza, compenetrar-se do espírito da religião, das leis e da história, dar vida às reminiscências do passado; eis a tarefa do poeta, eis os requisitos da nacionalidade da literatura”. Macedo compreende bem essa atitude e a encara como uma tarefa patriótica como notamos nesse trecho de sua narrativa:

[...] porque entendi que com este meu trabalho presto ao meu país um serviço e pago - lhe um tributo de patriotismo, pois que concorro com o meu contingente, fraco embora, para salvar do olvido muitas cousas e muitos fatos cuja lembrança vai desaparecendo. (MACEDO, 2005, p.23).

Antonio Candido (1997) define essa atitude dos escritores românticos em relação à literatura como elemento construtivo da busca pelo engrandecimento nacional como podemos ler a seguir:

Com efeito, a literatura foi considerada parcela dum esforço construtivo mais amplo, denotando o intuito de contribuir para a grandeza da nação. Manteve-se durante todo o Romantismo este senso de dever patriótico, que levava os escritores não a apenas a cantar a sua terra, mas a considerar as suas obras como contribuição ao progresso (CANDIDO, 1997, p.12).

Como vimos, a cidade física do Rio de Janeiro é o mote para o cronista evocar a história da cidade e para interpretar e sistematizar os seus signos. Isso tudo cria uma representação do espaço urbano por meio daquela cidade que Rama denomina cidade letrada e que tem por caráter fixar a cidade real. Isto é demonstrado através de muitos expedientes, dentre eles, incorporar características do discurso da cidade real tais como: a oralidade; através das músicas, das histórias populares e de tudo aquilo que está ligado ao universo não-letrado. Constatamos que essa é, não só uma atitude da cidade letrada, mas também do espírito artístico vigente na época, o Romantismo, que dentro do âmbito do discurso letrado também buscava constituir a nação através da literatura. 


\section{Referências}

CALVINO, Ítalo. As cidades invisíveis. Rio de Janeiro e São Paulo: O Globo e Folha de S. Paulo, 2003.

CANDIDO, Antonio. Formação da literatura brasileira. Belo Horizonte-Rio de Janeiro: Editora Itatiaia, 1997.

MACEDO, Joaquim Manuel de. Um passeio pela cidade do Rio de Janeiro. Brasília: Edições do Senado Federal, 2005.

PESAVENTO, Sandra Jatahy. O imaginário da cidade: visões literárias do urbano - Paris, Rio de Janeiro, Porto Alegre. Porto Alegre: Ed. Universidade/ UFRGS, 2002.

RAMA, Angel. A Cidade das Letras. São Paulo: Brasiliense, 1985. 